\title{
A mulher árbitra de futsal: entre a norma e a resistência
}

\author{
Aline Santos Nascimento* \\ Mário Luiz Ferrari Nunes**
}

\section{Resumo}

Este artigo visa identificar os processos de subjetivação que fixam o corpo da mulher árbitra de futsal como a diferença e as estratégias que elas empregam na tentativa de borrar as fronteiras que consolidam a modalidade como prática masculina. Apesar dos esforços e dos novos espaços de lutas que objetivam o direito à diferença e à igualdade dos direitos entre os gêneros, a mulher ainda enfrenta preconceitos e dificuldades. Ao serem marcadas como a diferença, atuam de forma ambivalente: ora em acordo com as normas estabelecidas ora mediante estratégias de resistência.

\section{Palavras-chave}

Mulher árbitra. Identidade e diferença. Futsal.

\begin{abstract}
This article seeks to identify the processes of individualization that try to keep the woman's body for Futsal referee as the difference in the sports scenario and the strategies they employ to blur the boundaries that attempt to consolidate the Futsal as a male practice. Despite the efforts and struggles of the new spaces that aim to the right to difference and equal rights between genders, women futsal referee still face prejudices and difficulties. To be marked as the difference, futsal referees act in an ambivalent way: sometimes in accordance with the standards established others through strategies of resistance.
\end{abstract}

\section{Keywords}

Woman referee. Identity and difference. Futsal.

\footnotetext{
* Professora da rede municipal de São Paulo, membro do grupo de pesquisas de Educação Física Escolar (FE) da Universidade de São Paulo (USP) e do grupo de pesquisas de Estudos Culturais em Educação Física do Centro Universitário Ítalo Brasileiro. E-mail: nasc_aline@hotmail.com.

** Doutor em Educação pela Faculdade de Educação da Universidade de São Paulo (USP), professor do Centro Universitário Ítalo Brasileiro e líder do grupo de pesquisas de Educação Física Escolar (FE) da Universidade de São Paulo (USP). E-mail: mario.nunes@usp.br.
} 


\section{Introdução}

A trajetória do século XX é marcada por grandes transformações sociais que implicaram em diversos movimentos identitários por reconhecimento, gerando novos olhares das Ciências Sociais para com temas e grupos culturais que, até então, estavam à margem dos estudos acadêmicos. Dentre eles, a história das mulheres emerge como um campo de estudo, que visa a compreender como em diferentes momentos históricos a sociedade enxerga o comportamento feminino, cria representações, legitima a sua inferioridade frente aos homens como algo "natural" e, ao mesmo tempo, possibilita resistências, mudanças e transgressões.

Nesse quadro, a participação das mulheres em espaços determinados culturalmente como de exclusividade masculina merece destaque. Isso ocorre no exercício da arbitragem esportiva de jogos de futebol, visto que nessa prática social encontram-se conjugadas ações marcadas pela divisão sexual, tanto por ser um fazer esportivo específico como por ser um trabalho remunerado economicamente. Ambos, lugares onde são ensinadas, expressas e perpetuadas maneiras de ser, práticas e valores patriarcais.

Se a luta das mulheres por reconhecimento tem produzido efeitos que abrem espaços para a sua atuação, na esfera esportiva isso não é diferente. Consonante com o surgimento dos primeiros movimentos feministas do final do século XIX, as investidas das mulheres nas atividades esportivas encontraram brechas para sua inserção por meio das políticas públicas sanitaristas realizadas pelos médicos higienistas. Essas proclamavam que a prática da atividade física, como caminhadas, andar de bicicleta e jogar tênis, desenvolveria melhores condições orgânicas, que tornariam as mulheres não apenas boas parturientes, mas serviriam, também, para embelezá-las, diferentemente do que era para os homens (GOELLNER, 2006). Para estes, a prática da atividade física tinha a ver com a construção da masculinidade. Daí a preferência recair na prática dos esportes possíveis de manifestar os dois polos do poder masculino tradicional: a força e a violência - como o futebol (DUNNING; MAGUIRE, 1997).

A presença da mulher no cenário esportivo é marcada por conquistas, resistências, transgressões e rupturas, e sua participação não se restringe apenas à prática. No caso específico do futebol, Goellner (2006) indica que há muito tempo as mulheres estão presentes nesse espaço masculino. Vão aos estádios, assistem a campeonatos, acompanham o noticiário, fazem comentários, divulgam notícias, são árbitras, atletas, técnicas, dirigentes, chefes de torcida 
organizada, enfim, participam do universo futebolístico de múltiplas formas, que abrem um amplo leque de possibilidade investigativa. Certamente, algumas dessas mulheres transgridem ao que convencionalmente se designou como sendo próprio de seu corpo e de seu comportamento, questionam a hegemonia esportiva masculina historicamente construída e culturalmente significada, enfrentam os preconceitos e, também, as estratégias de poder que estão subjacentes a elas. Talvez, por essas questões, investigar as ações da mulher árbitra de futebol seja uma tarefa relevante, árdua e de constante luta por significação. Pode-se afirmar que se trata de luta para garantir a equidade entre as partes por meio da constatação e afrontamento dos diversos signos e preconceitos que permeiam essa prática. Como as mulheres atuam em um espaço de hegemonia masculina? Como suas ações são celebradas, criticadas e justificadas? Quais as posições de sujeito que a cultura do futebol produz para a atuação das mulheres? Mais ainda! Sendo o espaço da arbitragem um local de atuação que envolve significados como justiça, austeridade, moral, entre outros, como as mulheres são posicionadas frente às suas decisões? São questões que mobilizam uma pesquisa para as mulheres e não sobre as mulheres em contextos materiais e históricos específicos.

$\mathrm{O}$ artigo localiza o campo epistemológico no qual assenta suas análises. Traz uma discussão sobre a identidade e a diferença e suas marcas na construção do corpo, tendo em vista que o corpo é local de construção e tentativas de fixação de identidades. Em seguida, apresenta uma pequena genealogia da trajetória esportiva da mulher e de sua presença na arbitragem do futsal. Por fim, analisa alguns excertos da história de vida de duas árbitras em atuação. A partir de Foucault (1992a), temos em mente que toda história é apenas outro texto dentro de uma profusão de textos e não uma garantia de uma significação única. O que se propõe é localizar o modo como se fala da mulher nesse espaço social, os efeitos que produz e vislumbrar mudanças e ações políticas transformadoras.

\section{A trajetória investigativa}

A pesquisa ancorou-se no método de coleta de história de vida divulgado por Poirier et al. (1999), que entendem o método como a possibilidade para articular as experiências de determinados sujeitos aos fenômenos sociais mais amplos em um tempo e lugar específicos sob influência de condições particulares. Foram escolhidas duas mulheres que estão em atuação no campo 
da arbitragem do futsal ${ }^{1}$. Uma pertence ao quadro de oficiais da Federação Internacional de Futebol Associados (FIFA) e a outra ao da Confederação Brasileira de Futsal (CBFS). Em relação à modalidade esportiva, apesar da maior exposição do futebol de campo nas mídias, entende-se que a participação da mulher no âmbito da arbitragem do futsal tem maior abrangência. Quanto aos sujeitos da pesquisa, optou-se por escolhas que possibilitassem pontos de vistas diferentes e, às vezes, contraditórios, capazes de contribuir para análises posteriores, pois elas atuam em entidades distintas. Gabriela exerce a atividade há nove anos, enquanto Luana atua há treze anos. A fim de salvaguardar a privacidade das colaboradoras, seus nomes estão denominados de forma fictícia.

A pretensão foi ver as condições nas quais a identidade e a diferença são vivenciadas pelos sujeitos e como são reguladas pela prática. De certo, outros sujeitos poderiam conferir outras formas de narrar-se, julgar-se e verse diante das condições culturais do futsal, bem como outro pesquisador conferiria outras significações ao estudo.

As entrevistas coletadas foram transcritas na íntegra, sem alterações na fala das depoentes e no formato de narrativas. No segmento do texto referente às análises, encontram-se alguns excertos extraídos da pesquisa. A análise dos dados empíricos foi confrontada com as produções dos Estudos Culturais e Estudos de Gênero, ambos sob o enfoque pós-estruturalista.

\section{As referências da trajetória: a questão de gênero}

As lutas liberais por democracia entre tantos movimentos de resistência de sujeitos em situação de dominação desdobraram-se em marchas, protestos, reivindicações e teorizações a respeito de uma disposição "natural" e inquestionável das coisas. $\mathrm{E}$ isso não foi diferente em relação aos estudos de gênero, que, gradativamente, vêm ganhando amplo espaço nas Ciências Sociais. Não há aqui qualquer pretensão em fazer um estado-da-arte sobre o

\footnotetext{
${ }^{1}$ Existem várias especulações quanto às condições do surgimento do termo futsal. Dentre elas, a de que se trata de uma modalidade brasileira que emergiu em função da ocupação dos campos de futebol de várzea pela crescente expansão imobiliária das grandes cidades. Após o seu reconhecimento pela Federação Internacional de Futebol (FIFA), nos anos 1990, a prática passa a ser chamada de futsal (SANTANA; REIS, 2003).
} 
tema, mas explicar de forma sintética as referências que compõem o campo da análise desta pesquisa e diferenciá-las de outras.

$\mathrm{O}$ conceito de gênero possibilitou deslocar o foco das tramas entre os homens e mulheres do âmbito biológico para o social. As análises das relações de gênero passaram a ser realizadas a partir de qualquer realidade histórica. Acontecimento que, sem dúvida, abriu caminhos para mapear as assimetrias e regimes excludentes, que se repetem em quase todas as culturas, e em múltiplas e complexas situações sociais ao longo da história humana, naturalizando qualquer questionabilidade.

No Brasil, esse mapa foi realizado por Helborn e Sorj (1999). As pesquisadoras apresentam um panorama dos estudos de gênero no país, evidenciando a ênfase em estudos que relacionam gênero com outras categorias sociais, como o trabalho, a violência, a família e a sexualidade nas classes populares. Sem atentar para aspectos epistemológicos que compõem as análises dos trabalhos, as pesquisadoras explicam e diferenciam a construção acadêmica do uso de termos como estudos da mulher, feministas e gênero. Também inventariaram as repercussões da trajetória dos estudos de gênero no país, além da contribuição desses para o conhecimento sociológico, destacando as peculiaridades da institucionalização dessa área de estudos no Brasil e a afinidade das pesquisas com os problemas formulados pelo campo político.

Entre os diversos estudos sobre o tema, as antropólogas Lamphere e Rosaldo (1979) indicam que a subordinação do gênero feminino é uma constante na humanidade e que as sociedades matriarcais podem ser consideradas como mito. Partem do princípio de que a consolidação da dominância masculina está comprometida com uma dada operação simbólica que marca sua distinção perante o outro gênero. Para as pesquisadoras, o dimorfismo sexual da espécie não impede que se reconheça o sexo como uma categoria historicamente datada. Assim, os conteúdos específicos que adquirem as categorias de gênero nos diversos contextos culturais manteriam esse princípio de ordenação, embora possam em substância ser diferentes. Destacam que as concepções sobre a diferença sexual não excluem o fato de que existe uma diferenciação nos corpos e que ela importa até o presente momento no modo como a humanidade se reproduz.

Relacionando essa problemática com o futebol, os estudos de Dunning e Maguire (1997) sobre comportamento das torcidas inglesas indicam que, dentre seus cantos de afirmação, encontram-se aqueles que enfatizam a conquista das mulheres dos torcedores adversários como forma de dominação. 
As músicas reproduzem ações históricas de conquistas em guerras, nas quais a reprodução com a mulher local (feita de forma violenta) é uma forma de conquista definitiva de um povo. A função reprodutora da mulher torna-a alvo de dominação pela continuidade da espécie, de um povo.

A problemática do gênero também pode ser lida nos termos de dominação masculina, segundo a interpretação de Bourdieu (2002). O sociólogo francês advoga que as relações entre homens e mulheres se ordenam por princípios de diferenciação assimétrica, organizando a economia das trocas simbólicas. Com isso, instaura-se uma assimetria entre os sexos, na qual homens são posicionados na condição de sujeitos, e as mulheres, na de objetos/ instrumentos. Ou seja, aborda-se o masculino/feminino como oposições em cadeias de diferenças, do mesmo modo que se opera com outas categorias de análise, como alto/baixo, rico/pobre, negro/branco etc. Nessa obra, isso fica visível, pois para Bourdieu as mulheres absorvem passivamente a "ordem masculina do mundo", na qual elas estão embebidas, como que em conluio com seus próprios dominadores (p. 22-23).

No entanto, os estudos de gênero têm superado a discussão primeira de igualdade e de diferenças, realizada mediante análises pautadas nas dicotomias e oposições. Com base em pressupostos pós-estruturalistas, ganham espaços os debates que compreendem o fato de que as realidades históricas são construídas, determinando o social, o cultural e as subjetividades, definindo o que é ser homem e o que é ser mulher (SCOTT, 1995). No pósestruturalismo, o sujeito é descentrado, as relações de poder não são estáticas, tampouco se encerram no binômio dominador/dominado, em função de o poder não estar localizado num lugar específico, pois as relações de força interagem entre si. Do mesmo modo, a diferença não é vista como algo que simplesmente difere de outra coisa, tomada como ponto de referência inicial - a norma. O advento pós-estruturalista faz valer que as diferenças sexuais são indissociáveis de uma demarcação discursiva². A categoria do sexo é vista como uma normatividade. Nesse sentido, o sexo não funciona apenas como uma norma, mas é parte de uma prática regulatória que produz os corpos que governa. Dito de outro modo, os corpos ganham inscrições culturais

\footnotetext{
${ }^{2}$ Para Foucault (1992b), o discurso não é apenas uma forma para descrever as coisas. Em suas concepções, o discurso fabrica as coisas. É um conjunto de enunciados que produz as formas de vermos e nomearmos o que vemos, determina o que pode ser dito e aquilo que deve ficar em silêncio, quem está autorizado a dizer, e, assim, proporciona efeitos sobre o sujeito.
} 
quanto ao masculino e ao feminino, além das possibilidades da sexualidade, produzindo formas de expressar desejos, prazeres, comportamentos, modos de aceitações e rejeições - que também são significadas na cultura. São essas inscrições que definem as identidades de gênero compostas e definidas por relações sociais e moldadas por redes de poder.

\section{As referências da trajetória: a identidade e a diferença nos Estudos Culturais e de Gênero}

Hall (2000) entende que a identidade não emerge de um centro interior, de um eu verdadeiro e único, mas da relação que cada sujeito estabelece com a sua cultura, com seus pares, com os significados nela produzidos, do diálogo com os conceitos e definições das coisas do mundo. Os sujeitos aprendem e buscam ideais identitários a partir dos sistemas simbólicos que os interpelam. Cabe reforçar que, para Hall (1997), a cultura é um campo de luta por significação. É um terreno em que diversos grupos disputam espaços pelo direito de se representar no âmbito social. É em meio a esse campo de contestação cultural que os grupos subjugados procuram fazer frente às imposições dos significados que sustentam os interesses dos grupos posicionados em assimetria superior. Por assim dizer, os textos culturais são o próprio local em que os significados são travados, negociados, partilhados, divulgados e fixados.

Vista por Hall (1997) enquanto sistema simbólico, é na cultura que as coisas são nomeadas mediante um processo de atribuição de sentidos e busca de estabilidade. Ao elaborar sistemas classificatórios, a cultura vai se organizando à medida que cria fronteiras simbólicas para excluir o que está fora do lugar e da ordem e, assim, configurar a desejada coesão social. É nesse jogo que se estabelece o normal, o adequado, a identidade e, por conseguinte, o anormal, o inadequado, a diferença. Logo, a construção da identidade e a da diferença se fazem simultâneas. Elas se dependem. Sem uma não é possível que haja a outra.

Pode-se dizer que a identidade é resultante de um processo estabelecido dentro de uma ordem relativa que vem a mudar à medida que a situação que o sujeito vive se altera. Pode-se sempre "perdê-la ou ganhá-la", dependendo de quem ou de como os outros olham para o indivíduo e como ele é falado. Ou seja, ele poderá sustentá-la ou abandoná-la, embora suas condições de 
existência sejam mais ou menos determinadas por um sistema simbólico (HALL, 2000).

A construção desse sujeito é feita de múltiplas identidades, como as de gênero, raça, classe social, religião etc. Nessa construção, ora o sujeito é a identidade ora ele é a diferença (SKLIAR, 2003). Isso o torna fragmentado, fluido, pois ora ele está em situação de dominação ora não está. Além disso, é nesse jogo que se afirmam as políticas de identidade em busca de espaço e reconhecimento cultural, enfim, do poder de se representar. Essas explicações reforçam a noção de que a identidade não é fixa, tampouco pode ser compreendida como a norma. São as lutas pelo poder de significar que produzem práticas de regulação que tentam marcar a identidade e localizar para corrigir ou expurgar a diferença. Ou seja, as identidades do sujeito são definidas pela sua diferença em relação a outras identidades e não por algo que lhe é próprio. A fixação da identidade se dá no momento em que os sujeitos recebem marcadores simbólicos que fazem com que aparentem ser sua própria essência como a cor da pele, a posse de bens materiais, os órgãos sexuais, suas habilidades etc.

No tocante à identidade de gênero, seu eixo de identificação, socialização e pertencimento gira em torno dos contornos corporais marcados pela distinção biológica presente na gestualidade, voz, cabelo e órgão genital. É no domínio do corpo humano que se investem sentidos, criam-se teorias para comprovar distinções físicas, psíquicas e comportamentais. Esse domínio é atravessado por instituições, práticas discursivas e não discursivas que atrelam verdade e poder, que definem sua própria historicidade. A representação do gênero é a justificativa para consolidar os lugares e as possibilidades de atuação social do feminino e do masculino (LOURO, 2011).

O corpo, seus significados e representações são produzidos na e pela cultura. Isso implica romper com os determinismos naturalistas que ao longo da história atribuíram-lhe classificações e fomentaram formas de explicá-lo e, por conseguinte, meios de educá-lo, cuidá-lo, curá-lo etc. Enquanto artefato cultural, ele é constituído em meio às relações de poder que lhe conferem diversas marcas em diferentes momentos e espaços sociais, contribuindo com os modos pelos quais os sujeitos são constituídos, e se tornam pertencentes aos diversos movimentos identitários que cada grupo cultural produz. Movimentos que atribuem significados aos sujeitos acerca de quem eles são, foram e deverão ser.

Ao problematizar a construção do corpo, Foucault (1992a) nos ajudou a compreender que nossa gestualidade é uma construção historicamente 
datada e produzida nas diversas instituições sociais, de forma a conhecê-lo para controlá-lo e, assim, torná-lo dócil e produtivo. Para o filósofo, o controle da sociedade não se dá apenas pela ideologia ou consciência, mas começa no corpo e nele se investem estratégias que individualizam e subjetivam os sujeitos. Suas análises contribuem para que problematizemos os significados que a cultura ocidental capitalista atribui aos corpos, às narrativas que sobre eles ocorrem e às práticas sociais que os operam e sobre eles produzem efeitos. É nesse emaranhado de produções de sentido de quem somos e de quem são os outros, do que é um corpo desejável e aceitável e de qual não o é, que se encontra a produção do corpo feminino, do corpo da mulher árbitra.

Beleza, maternidade, delicadeza, sensibilidade, meiguice, ternura, proteção, feminilidade são significados atribuídos que contribuem para a normatização do que venha a ser mulher. Se atentarmos a isso, verificaremos que a sua significação na sociedade moderna, ocidental, industrializada, proporcionou-lhe uma segregação social e política, restringindo-a, muitas vezes, ao ambiente doméstico. Lócus no qual essas conotações imperam e as encerram em seus corpos. Costumeiramente, ela foi representada como a "rainha do lar", cabendo-lhe, por conta disso, executar funções preceptoras. Essa representação the conferiu, também, a posição de sujeito "boa mãe e boa esposa", determinando-lhe a função do cuidado da casa, do lar e a educação de seus filhos (GOELLNER, 2003; 2006). Os efeitos observados nas descrições corriqueiras acerca da mulher incidiram no seu reconhecimento como um ser sensível e frágil. Em oposição, ao homem coube a função de liderança, proteção e provisão da família, associada às características e atributos de força, resistência e coragem.

Para Louro (2011), essa construção foi e vem sendo produzida a partir de múltiplos discursos que afirmam que o lugar da mulher deve ser restrito ao âmbito do privado. O que contribui, de certo modo, a desqualificá-la para atuar no espaço público, a torná-la invisível em certos lugares ou provocar medo, desejo, repulsa e ansiedade pela sua presença em outros. Apesar de há tempos muitas mulheres exercerem atividades fora dos lares, atuando nas fábricas, lavouras e oficinas e, mais recentemente, ocuparem funções em lojas, escritórios, escolas, hospitais, suas ações, em geral, eram e ainda são determinadas e controladas na maioria desses espaços e ao longo do tempo por uma ordem do discurso masculino.

Esse estofo teórico remete-nos de volta à cultura como sistema de significações que estabelecem os significados das coisas por meio da 
representação. São esses significados que dão sentido às vidas dos sujeitos, que os posicionam e constroem suas identidades. Tais definições nos ajudam a entender o futsal como uma produção cultural e, como tal, se insere em uma dimensão de território em conflito, em luta pelo poder de controlar o significado.

Enquanto artefato cultural, o futsal produz significados sobre o tipo de pessoa que dele se utiliza. Determinado culturalmente como masculino, esse esporte atua na fabricação de corpos que possam superar situações adversas, como as de contato corporal, enfrentamento verbal, exposições constantes às críticas de aficcionados, superação dos limites psicológicos e biológicos, circulando o discurso do masculino como norma.

A presença da mulher, do Outro cultural nesse espaço produz instabilidade na ordem discursiva. Afinal, esse espaço não lhe pertence. Decorre disso questionar quais são as estratégias que tentam regular e normatizar as condutas de seus sujeitos, enquadrando as mulheres como a diferença, avaliandoas como incompletas e impróprias para atuarem como árbitras. Também, de que modo a presença da mulher contraria as normas e os mecanismos de fixação de identidades que a hegemonia esportiva masculina estabelece como referência e como ela (árbitra) pode produzir formas híbridas de ser e ressignificar a prática e, por conseguinte, recusar a perspectiva da identidade e afirmar a diferença.

\section{Trajetórias: a mulher na arbitragem esportiva}

A participação das mulheres no cenário esportivo oficial só foi possível a partir da segunda edição dos Jogos Olímpicos Modernos, realizados em 1900, na cidade de Paris. Sua presença não ficou isenta de protestos e manifestações contrárias, inclusive pelo Barão de Coubertin, principal idealizador e incentivador dos jogos. Nesse período, as vozes dominantes enfatizavam que sua participação poderia vulgarizar e desestabilizar um terreno criado e mantido pelo domínio masculino, justificativa assentada na biologia do corpo e do sexo, atestando a superioridade masculina no tocante ao uso da força física (GOELLNER, 2003).

$\mathrm{Na}$ transição dos séculos XIX/XX, a educação do corpo voltava-se ao desenvolvimento e fortalecimento da construção de um espírito nacionalista, na medida em que era observada como potente para a construção da 
gestualidade eficiente dos sujeitos. Tais objetivos visavam aumentar a produção no trabalho com maior rapidez, eficiência, e desmobilizar suas forças políticas. Enfim, a conhecida expressão formulada por Foucault: a produção de corpos dóceis e úteis, ideais que condiziam com os pressupostos da industrialização, racionalização da vida, construção das metrópoles, expansão do capital, controle das populações, além, é claro, da construção de pertencimento a uma identidade nacional. A partir disso, começam a proliferar nas cidades os clubes recreativos, as agremiações, as federações com os seus campeonatos esportivos e as exibições atléticas, locais destinados ao rendimento de corpos educados, desenhados pela exercitação física e legitimados pelos discursos médicos e dos planejadores sociais (GOELLNER, 2003). Essas instituições e eventos alinhavam-se aos ideais de desfrute da vida nas grandes cidades, e, rapidamente, expandiram essa prática de espetáculo restrito às elites a elemento cultural cada vez mais popular no cotidiano e presente na educação do restante da população, elementos que serviram para a expansão de certos modos de ser, pensar e agir, predominantemente masculinos.

No Brasil, a partir do Decreto de lei 3.199 de 1940, oficializou-se a proibição para mulheres praticarem desportos incompatíveis com as condições de sua natureza (sensível, frágil, dócil etc.), dentre eles o futsal. A mudança somente ocorreu com a deliberação $n^{\circ}$. 7/65 de 1979, concedendo-lhe o direito. No futsal, sua participação foi permitida pela Federação Internacional de Futebol de Salão (FIFUSA), em 1983. Essa inserção é considerada uma transgressão, pois subverte a ordem de um espaço ao trazer consigo outros valores embutidos, como o corpo erotizado, a graciosidade, a beleza e a sensualidade (GOELLNER, 2006). Uma ameaça àquele status quo.

Apesar das condições de emergência da arbitragem feminina terem sido construídas ao longo do século XX, no Brasil esse trabalho é relativamente novo. Manoelita Valinho Rodrigues (1935) foi uma das primeiras a realizar, em 1980, o curso de arbitragem na Federação Paulista de Futebol de Salão (FPFS), trabalhando na entidade até 2011.

É importante destacar que, nos anos 1980, a mulher só poderia exercer a função de anotadora e cronometrista, pois lhe era negado o direito de arbitrar uma partida oficial, condição que só foi alterada em 1997. A fim de expandir a arbitragem feminina, em meados do ano 2000, Inês dos Santos (1961), exdiretora do departamento feminino da CBFS, sugeriu que Paraguassu Fisch Figueiredo (1947), ex-diretor de árbitros da CBFS, elaborasse um quadro 
feminino de oficiais. Em 2001 ${ }^{3}$, abriram-se inscrições para as indicações ao quadro (que deveriam ser feitas pelas federações de cada estado). Apesar dos esforços, o quadro só foi efetivamente criado em 2002, quando foi possível ver Rita de Cássia Lima-SP (1963) atuar na fase eliminatória da Taça Brasil ${ }^{4}$, na cidade de Valinhos-SP, e Maria Jaqueline de Oliveira Cammarota-DF (1961) atuar na fase final desse evento, na cidade de Brasília-DF. Cabe destacar que ela atuou na finalíssima, ao lado do árbitro Adilson Mattos (1962).

A presença definitiva da mulher árbitro nesse espaço ocorreu em 2003, na cidade de Chapecó-SC, quando da realização da $1^{\text {a }}$ Taça Brasil de Clubes Feminina, categoria sub 20. A arbitragem nesse evento foi conduzida apenas por mulheres, sendo elas: Alane Jussara da Silva Lucena; Maria Jaqueline Cammarota; Ana Lucia Martins de Castro; Claudia Martins da Paz; Katiucia Meneguzzi dos Santos; Gisele Torri; Marcia Aparecida Marcondes dos Santos; Arilete Favaretto e Elieth Fátima Dambrós Freitas.

Para coroar a boa atuação das mulheres (entende-se aqui negociar a legitimidade de sua presença), a FIFA cria em 2007 seu quadro feminino de oficiais, dando espaço a quatro brasileiras indicadas pela CBFS: Renata Neves Leite, Giselle Torri, Katiucia Meneguzzi e Alane Lucena (DINIZ, 2011). Renata Leite, que em 2012 esteve presente na Copa do Mundo realizada na Tailândia, foi eleita a segunda melhor árbitra do mundo pela AGLA Futsal Awards ${ }^{5}$, concorrendo com mais nove árbitros homens.

\footnotetext{
${ }^{3}$ As oficiais Alane Jussara Lucena e Renata Neves Leite já atuavam na CBFS pelo quadro masculino entre os anos 2001 e 2002.

${ }^{4}$ A Taça Brasil é uma das competições mais tradicionais da CBFS. A competição reúne os campeões dos Estados.

${ }^{5}$ Premiação máxima do futsal mundial outorgada pela Federação Internacional de Futebol (FIFA) e organizada pelo site Futsal Planet. Várias categorias concorrem às indicações: melhor jogador (masculino e feminino); melhor goleiro e melhor jogador jovem (sub-23); melhor treinador (seleções e clubes); melhor árbitro; melhor seleção; melhor clube; vitória por seleções e clubes. Exceção à premiação de melhor jogador, as demais categorias não são divididas em masculino e feminino. O que se nota nos dados das suas indicações é a esmagadora presença dos homens na lista dos indicados. Pode-se afirmar que espaços como esse se constituem e são constituídos por uma ordem do discurso masculina.
} 


\section{Trajetórias: a vida de duas mulheres na arbitragem esportiva}

Reconhecida como uma das maiores protagonistas do futsal, atuando como atleta e depois como árbitra, Gabriela relata ser desprivilegiada. Afinal, se há pouca divulgação do futebol feminino, o que dizer do futsal. Isso indica que o status profissional alcançado nesse esporte não lhe confere força suficiente para combater a relação de desigualdade entre os gêneros presentes no universo da arbitragem.

Os envolvidos na arbitragem não te valorizam muito. Não tem confiança no seu trabalho [...] árbitros conceituados falam que você está bem, que está na hora e você não vê isso acontecer. Então, eu acho que a coisa vem lá de cima mesmo. Na falta de confiança em uma mulher (Gabriela).

Assim como a colega, Luana antes atuou como atleta e reforça o discurso acerca da presença da mulher que exerce autoridade dentro de um espaço privilegiado pela identidade masculina como um fator de grandes conflitos e cobranças.

Os dirigentes gostam de mulher apitando? Não! Tem atleta que gosta de mulher apitando? Não! Tem pai que olha pra mim e diz: "Vai lavar roupa!". Eu não aprendi lavar roupa. "Vai cozinhar!". Eu não aprendi cozinhar. Eu estudei para ser árbitra, isso eu sei fazer [...] essa é a mentalidade que a sociedade passa [...] mulher não vai até estádio de futebol, fica em casa assistindo novela (Luana).

Essa desvalorização e falta de reconhecimento encontram forças no modo como os demais sujeitos envolvidos nessa prática enunciam a presença da mulher no cenário esportivo. Assim como Gabriela reclamou da cobrança em relação a sua atuação, Luana reforça que a questão não está relacionada apenas ao caráter e à moral, como ocorre na arbitragem masculina. Ela escancara o incômodo que a presença da mulher nesse cenário causa. A exigência quanto ao seu desempenho expressa os significados e as fronteiras construídas na cultura ocidental que marcam a distinção entre o feminino e o masculino.

[...] quanto mais importante o jogo, maior é a cobrança em cima da mulher. A mulher não pode errar (Gabriela). 
[...] não é porque ela é árbitra de futsal, é porque ela é mulher. Não importa se eu sou uma empresária de sucesso ou uma professora [...] se ele está num patamar e olha pra mim, ele não me olha única e exclusivamente como profissional da área esportiva, ele olha pra mim enquanto mulher (Luana).

Em certa medida, essas falas reforçam os discursos hegemônicos que ditam que suas ações se limitam ao âmbito privado e do lar. A mulher considerada inapta para exercer as funções da arbitragem é marcada por um estatuto de verdade que regulamenta os locais de sua atuação. Contudo, a ambivalência se faz presente, pois não é difícil perceber que essas mulheres, diante das representações negativas a elas atribuídas, operam uma transformação de si mesmas. Com a ajuda de Larrosa (1994), pode-se dizer que os fragmentos desses textos indicam que as tecnologias do eu estão associadas aos enunciados produzidos pelos sujeitos e produzem autorreflexão, criam, regulam e modificam uma experiência subjetiva de si mesmo. Em tempos de luta por reconhecimento da capacidade das mulheres, elas fragmentam a si mesmas. São duas identidades distintas: profissional e mulher.

Sendo a representação do gênero uma prática social, essas histórias de vida reforçam os modos de como a educação do corpo é realizada desde a mais tenra idade. Gabriela recorda que na infância vivenciou a prática do futebol em grande parte do tempo e não havia nenhum problema com os meninos, pois jogava bem. Entretanto, seus pais não aceitavam vê-la chutando bola pela rua, o que não a incomodou. O mesmo aconteceu com Luana. Irmã caçula e distante da mais velha, teve a oportunidade de interagir apenas com o irmão. Esse fato lhe garantiu a apropriação de certos saberes condizentes com as práticas corporais denominadas masculinas, tais como jogar bola, peão, soltar pipa etc., causando receio e censura familiar. Suas ações eram consideradas um desvio às condutas femininas.

Na minha rua só tinha menino mesmo, as únicas meninas eram minhas duas irmãs, que a gente não se dava muito bem e aí eu tinha brincadeiras de menino [...] meus pais tinham certa resistência, não gostavam. Mas não tinham muita opção [...] a menina nasce e todo mundo imagina ela brincando e fazem isso, dão bonecas para ela brincar (Gabriela).

[...] nenhuma família gosta quando sua filha diz: "Eu vou jogar bola". Quando eu nasci, eu ganhei uma boneca e não uma bola. Minha mãe queria me ver de vestidinho na rua sentada na calçada, 
olhando o povo passar e não me ver de tênis com o joelho todo ralado jogando bola [...] um filho quando nasce à primeira coisa que ele vai ganhar é uma camisa do clube que provavelmente o pai dele torce, não é nem o clube que a mãe torce [...] A menina quando nasce [...] ganha de presente uma boneca e um vestido. Como se fosse completamente inviável uma menina usar uma camisa de clube e brincar de bola (Luana).

As lembranças de como essas mulheres foram constituídas em seio familiar enaltecem a produção de um corpo relacionado à educação e ao gênero. Meyer (2010) entende que educar engloba um complexo de forças e de processos (os meios de comunicação de massa, os brinquedos, a literatura, o cinema, a música etc.) no interior dos quais indivíduos são transformados em - e aprendem a se reconhecerem como - homens e mulheres. Neste sentido, a cultura constrói e distingue corpos e sujeitos femininos e masculinos.

Esses processos também ocorrem no âmbito da atuação da mulher árbitra. Por lá, elas se materializam na construção dos corpos, e a sua regulação tornase uma necessidade.

O teste físico é o mesmo e nós não temos a mesma capacidade física e muscular do homem. Enquanto os meninos trabalham na linha do último homem no futsal eu trabalho dois passos após a linha, porque se o jogador vira e sai no contra-ataque, eu vou conseguir acompanhar ele porque eu saí a dois passos à frente. Quando ele chegar pra bater na bola, eu vou estar na mesma linha que ele. Então, eu vou observar tudo. São maneiras que você procura de se defender e de se adaptar (Luana).

Foucault (1992a) nos ajuda a compreender os investimentos que são realizados sobre os corpos, valorizando suas forças, a dinâmica do corpomáquina, a anátomo-política como sua tecnologia disciplinar. O corpo está submetido a uma racionalidade que considera a perspectiva anátomofuncional como critério último de verdade. Essa racionalidade apresenta-se na classificação advinda do exame. Isso fica evidente em um lugar onde a valência física e o desempenho compõem a norma.

O que é possível observar na fala de Luana, ao ditar as diferenças biológicas entre homens e mulheres no futsal referentes à força, velocidade, agilidade e habilidade, são as estratégias de poder frente à força produtiva que não apenas nega, impede, coíbe, mas também produz sujeitos, fabrica corpos dóceis, induz comportamentos e incita a posição inferior dos sujeitos. 
Sobre o poder, Foucault (1992b) entende que ele é uma forma de regulação e controle para governar a conduta humana. Mas, também em Foucault, encontramos a possibilidade da resistência, de afirmação da vida, do corpo. Para estar ali, Luana modifica o jogo, cria possibilidade de atuar dentro dos discursos normativos, ao mesmo tempo em que investe em estratégias de subversão à ordem sem, no entanto, implodi-las.

Nessa vertente, as tecnologias de subjetivação presentes nas relações de poder inseridas na arbitragem, ou seja, o modo como a mulher árbitra aprende a ver-se, julgar-se, governar-se e discursar sobre si, têm formado, de fato, sujeitos obedientes às normas (LARROSA, 1994). O processo de fabricação dos sujeitos é contínuo e geralmente muito sutil, quase imperceptível. Assim, o olhar deve se voltar especialmente para as práticas rotineiras e comuns, os gestos e as palavras banalizados precisam se tornar alvos de atenção revogada, de questionamento e, em especial, de desconfiança (LOURO, 2011). A tarefa mais urgente talvez seja exatamente essa: desconfiar do que é tomado como natural.

Antigamente, vamos dizer assim, a aparência das meninas era complicada, então, era o "sapatão" se jogasse bola. Isso também mudou muito hoje. As pessoas olham e não falam sobre isso (Gabriela).

A mulher envolvida com o esporte [...] ela não deve se masculinizar para estar ali [...] não preciso gritar com o cara como ele esta gritando comigo [...] a arma que as mulheres têm para derrubar algumas coisas é a delicadeza e a questão da feminilidade [...] ela pode ser delicada, feminina, porém, ela precisa saber impor respeito (Luana).

Ao desconfiar desse modo natural de ser, Goellner (1999) considera que o corpo feminino que se transforma para exercer determinada função esportiva, muitas vezes, sofre atribuições de características viris que não apenas questionam a beleza e a feminilidade da mulher, mas também colocam em dúvida a autenticidade do seu sexo. Ao duvidar, o discurso tradicional impõe o conceito de um corpo ideal, capaz de se enquadrar nos padrões da docilidade, fragilidade e, principalmente, na atualidade, na magreza. Um corpo feminino que se distancia desse padrão é logo questionado. Não à toa diversas são as tentativas de exclusão das mulheres desse cenário ou da segregação de sua prática. 
Não tão distante, ser excluída significaria não estar condizente com as normas estabelecidas pelo grupo social em que o sujeito se insere. Hábitos, costumes, condição financeira e sua participação social não se assemelham aos da classe hegemônica. Para Skliar (2003), excluir acaba se tornando a maneira mais fácil de resolver o problema da presença da diferença.

Discutir o espaço conquistado pelas mulheres e as relações de gênero e corpo continuam sendo, sem dúvida, um grande desafio. Apesar das grandes reivindicações feministas, há muitas barreiras que inviabilizam uma identidade. Nas histórias de vida investigadas, as mulheres se constituem a partir dos discursos dominantes.

Eu venho de um estado que segundo algumas frases não deveriam ser tão machistas porque toda paraibana é "mulher macho sim senhor" $[\ldots]$ embora essa frase exista [...] eles a veem com outros olhos que eu não gosto. A "mulher macho" é no sentido da guerra, da vontade, da briga, do lutar pelo querer (Luana).

Nesse caso, o preconceito é visto como uma forma de construção do Outro, a partir da própria neutralização do mesmo. Implica a negação do individuo diferente e, no mesmo movimento, a afirmação da própria identidade como superior/dominante. É nessa troca que, por vezes, e durante anos, as mulheres, os negros, os pobres, os homossexuais e tantos outros fugiram dos padrões estabelecidos pelas identidades normatizadas (masculina, heterossexual, burguesa, cristã). Seus corpos, seus signos, suas representações tornaram-se representações inferiores, incompletas, díspares (GOELLNER, 2010).

A mulher, enquanto representação, ao longo do tempo vem se constituindo a partir do olhar alheio, do poder que fabrica corpos fragmentados obedientes às leis, às normas e atentos a si mesmo. Mecanismos que tornam visíveis e eficazes as ações da mulher árbitra.

Na minha estreia em um jogo de um time de camisa eu me senti pressionada. Porque era o primeiro jogo de influência e eu não podia tomar uma atitude drástica ali. Eu tive que aguentar aquela pressão o jogo inteiro e tentar me concentrar pra tentar levar o jogo dentro da normalidade. Que se o jogo saísse da normalidade era exatamente porque era uma mulher que estava apitando aquele jogo (Gabriela). 
Para Nunes e Shigunov (2002), as concepções que norteiam a prática do árbitro de futebol denunciam que as pessoas, em suas atuações esportivas, seja torcendo, dirigindo ou como atleta, são incapazes de compreender a figura do árbitro, tampouco a sua função. A ação do árbitro é vista meramente como alvo de protestos e agressões, sejam elas quais forem. É necessário que se frise que, independentemente das questões de gênero, a equipe de arbitragem tem somente uma fração de segundo para ver, interpretar, raciocinar, analisar e emitir o sinal da sua decisão, sem poder rever a ação. Se falhar, seu julgamento será impreciso. No caso da mulher árbitra, isso parece produzir outros efeitos, bem distantes dos sentimentos de moral e de justiça que são atribuídas à equipe de arbitragem masculina.

\section{Considerações}

Introduzida em 1868 no futebol, a arbitragem era exercida apenas mediante a consulta dos capitães das equipes. Com as complexidades nas regras e a sua expansão global, a arbitragem passou a ser preponderante para que os princípios burgueses de igualdade e mérito prevalecessem no futebol. Faz-se crer que, para ser reconhecido dignamente como árbitro esportivo, basta aplicar as regras do jogo. As narrativas aqui apresentadas contribuíram para se verificar que para a mulher isso não é o suficiente. Sua luta por reconhecimento é maior.

O significado do que venha a ser sujeito-árbitro tem relação com construções discursivas históricas, sociais e culturais, hoje claramente influenciadas pela mídia. Para tanto, aquele que se aventurar por essa vereda profissional sabe bem os discursos que lhes são dirigidos quanto a sua eficiência e caráter. Para as mulheres isso vai além. Elas têm que enfrentar outras formas de significação, que envolvem a produção da identidade e da diferença. A presença da mulher nesse cenário amplia as formas de marcação da diferença.

Os sujeitos desta pesquisa se constituíram no interior de certos aparatos de subjetivação, tornando-se corpos dóceis e adestrados, regulados em função da cultura que se estabelece na prática corporal na qual a norma é heterossexual e masculina, o que acaba por construir um estatuto de verdade no qual a virilidade e a força são os atributos necessários para o exercício e o controle da arbitragem. 
As análises aqui formuladas evidenciam que os diferentes discursos acerca da mulher, produzidos em outros lugares, estão fortemente presentes, reforçando a imposição de um modelo ideal do que venha a ser mulher. De certo modo, essa reverberação torna esse espaço mais um campo de luta para a construção de uma sociedade mais justa e mais igualitária, não só no que se refere ao gênero, mas em todos os seus níveis de relação.

Apesar dos esforços e dos novos espaços de lutas que objetivam o direito à diferença è̀igualdade dos direitos entre os gêneros, a mulher ainda enfrentará preconceitos e dificuldades que a hegemonia masculina da modalidade estabelece. As mulheres desta pesquisa aceitam as imposições do treinamento físico, ao mesmo tempo em que criam estratégias de sobrevivência. Mantêm a postura corporal ereta para impor o respeito da autoridade, ao mesmo tempo em que procuram manter a elegância e a graciosidade de seu corpo. Ao serem marcadas como diferença, essas mulheres árbitras atuam frente às normas estabelecidas pelos processos de subjetivação e regulação de forma ambivalente entre a resistência e a normalização.

\section{Referências}

BOURDIEU, Pierre.

(2002) A dominação masculina. Rio de Janeiro: Bertrand Brasil.

\section{DINIZ, Marcos}

(2011) Quadro de Arbitragem Feminina tem Brasileiras. Disponivel em: http:// www. futsal.com.br/noticias/noticia. asp?NumeroID=11519\#. Acesso em 23 de agosto de 2011.

DUNNING, Eric; MAGUIRE, Joseph.

(1997) As relações entre os sexos no esporte. Revista de estudos feministas. vol 5, n. 2, p. 321-348.

FOUCAULT, Michel

(1992a) A palavra e as coisas. Rio de Janeiro: Martins Fontes.

(1992b) Microfísica do poder. 10. ed. Rio de Janeiro: Graal.

GOELLNER, Silvana Vilodre

(1999) Imperativos do ser Mulher. Motriz, v. 5, n. 1 , p. 40-42.
(2003). 0 esporte e a espetacularização dos corpos femininos. Labrys Estudos Feministas. Disponível em: http://www. tanianavarroswain.com.br/labrys/labrys4/ textos/silvana1.htm. Acesso em 23 de agosto de 2011.

(2006). “Na Pátria das Chuteiras as mulheres não tem vez". In: VII Seminário Internacional Fazendo Gênero - Simpósios Temáticos. Santa Catarina: UFRGS. Disponivel em: http://www. fazendogenero.ufsc.br/7/artigos/S/Silvana_ Vilodre_Goellner_21.pdf. Acesso em 30 de setembro de 2011.

(2010). "A produção cultural do corpo". In: Guacira Lopes Louro; Jane Felipe; Silvana Vilodre Goellner. (Orgs.); Corpo, Gênero e Sexualidade: Um debate contemporâneo na educação. 5. ed. Petrópolis: Vozes. p. 28-40.

HALL, Stuart

(1997). A centralidade da cultura: notas sobre as revoluções culturais do nosso tempo. Educação \& Realidade.v. 22, n. 2, jul/dez, p. 15-46. 
(2000). "Quem precisa de identidade?" In: Tomaz Tadeu Silva (Org. e Trad.); Identidade e diferença: a perspectiva dos estudos culturais. Petrópolis: Vozes. p. 103-133.

HEILBORN, Maria Luiza; SORJ, Bila.

(1999). "Estudos de gênero no Brasil". In: Sérgio Miceli (0rg.); 0 que ler na ciência social brasileira (1970-1995). ANPOCS/CAPES. São Paulo: Editora Sumaré. p. 183-221.

LARROSA, Jorge

(1994). "Tecnologias do eu em educação". In: Tomaz Tadeu Silva (Org.); 0 Sujeito da Educação: Estudos Foucaultianos. Petrópolis: Vozes. p. 35-86.

LOUR0, Guacira Lopes

(2011). Gênero, Sexualidade e Educação: Uma perspectiva pós-estruturalista. 12. ed. Petrópolis: Vozes.

MEYER, Dagmar Estermann

(2010). "Gênero e educação: teoria e política". In: Guacira Lopes Louro; Jane Felipe; Silvana Vilodre Goellner (Orgs.); Corpo, Gênero e Sexualidade: Um debate contemporâneo na educação. 5. ed. Petrópolis: Vozes. p. 09-27.

NUNES, Renildo; SHIGUNOV, Viktor (2002). Auto-estima do árbitro de futebol profissional do estado de Santa Catarina. Revista da Educação Física UEM. v. 13, 20 semestre. p. 71-79.
POIRIER, Jean; CLAPIER-VALLADON, Simone; RAYBAUT, Paul

(1999) História de vida: teoria e prática. Lisboa: Celta.

ROSALD0, Michelle Zimbalist; LAMPHERE, Louise (org.)

(1979) A mulher, a cultura, a sociedade. Rio de Janeiro, Paz e Terra.

SANTANA, Wilton Carlos; REIS, Heloisa Helena Baldy

(2003). Futsal Feminino: perfil e implicações pedagógicas. Revista Brasileira Ciência e Movimento. v. 11, n. 4, out/dez, p. 45-50.

SKLIAR, Carlos

(2003) Pedagogia (improvável) da diferença: e se o outro não estivesse ai?. Rio de Janeiro: DP\&A.

SCOT, Joan Wallach

(1995) Gênero: uma categoria útil de análise histórica. Educação e Realidade. Porto Alegre, vol 20, n², jul/dez, p. 71-99.

\section{Recebido em}

fevereiro de 2014

\section{Aprovado em}

abril de 2014 